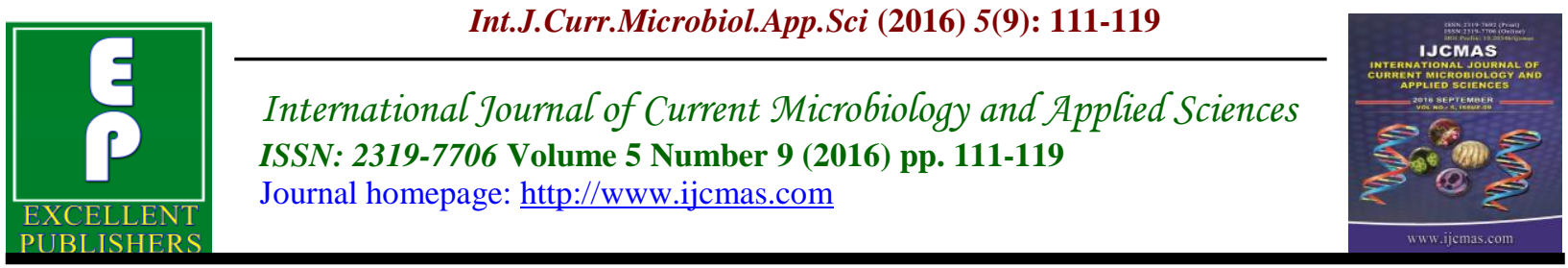

Original Research Article

http://dx.doi.org/10.20546/ijcmas.2016.509.013

\title{
Antibiotic Resistance Patterns of Isolated Bacteria from Government and Private Poultries Water Samples in Ado-Ekiti
}

\author{
A.T. Odeyemi* and O.E. Omotoso \\ Department of Microbiology, Ekiti State University, Ado-Ekiti, Nigeria \\ *Corresponding author
}

Keywords

Poultries, antibiotics resistance, raw water, antibiotic treated water.

\section{Article Info}

Accepted:

08 August 2016

Available Online:

10 September 2016

\section{A B S T R A C T}

This study was carried out to isolate and identify antibiotic resistant bacteria from the raw water, antibiotic treated water and droppings of government and private poultries in Ado-Ekiti, Ekiti State. The total bacterial and coliform counts were done using pour plate technique while the susceptibility of the isolated microbes was determined using disc diffusion method. The mean bacterial estimation of raw water, antibiotic treated water samples and fowls feacal droppings ranged $0.6 \mathrm{x}$ $10^{4}-0.2 \times 10^{5} \mathrm{CFU} / \mathrm{ml}, 0.7 \times 10^{4}-0.4 \times 10^{5} \mathrm{CFU} / \mathrm{ml}$ and $7.8 \times 10^{4}-13.3 \times 10^{5} \mathrm{CFU} / \mathrm{ml}$ respectively for private poultries; while the mean bacterial values of Government (EKSU) poultry ranged $0.7 \times 10^{4}-0.3 \times 10^{5} \mathrm{CFU} / \mathrm{ml}, 1.0 \times 10^{4}-0.9 \times 10^{5} \mathrm{CFU} / \mathrm{ml}$ and $4.7 \times 10^{4}-6.3 \times 10^{5} \mathrm{CFU} / \mathrm{ml}$ respectively. A total of two hundred bacteria were isolated, belonging to eleven genera; among which Staphylococcus aureus and Escherichia coli had the highest incidence of 61(30.5\%) and 48(24\%), while Enterobacter had least incidence of 1(0.5\%). Other organisms isolated include species of Micrococcus, Pseudomonas, Klebsiella, Bacillus, Proteus, Acetobacter, Streptococcus and Serratia. The result of antibiotic sensitivity test revealed that Escherichia coli exhibited highest resistance to Gentamycin (73\%) and lowest to Ofloxacin (54\%). Pseudomonas spp. showed resistance range of 45\% (Ofloxacin) to $80 \%$ (Nalixidic acid), while Klebsiella, Proteus, Enterobacter, Serratia and Acetobacter were more susceptible to Ofloxacin. The gram positive were more susceptible to Chloramphenicol, except Bacillus which was more susceptible to Gentamycin and Augmentin. Streptococcus spp. also resisted the activity of Cotrimoxazole $(83 \%)$. This study therefore emphasis on the need for proper usage of antibiotics in poultries under appropriate veterinary agency, so as cub the emergence of antibiotic resistant bacteria from poultries and also recommends the use of Ofloxacin for hacteria infections.

\section{Introduction}

Poultry farming is the raising of domesticated birds such as chickens, turkeys ducks and geese, for the purpose of farming meat or eggs for food. Poultry are farmed in great number with chickens being the most numerous (San, 2003). Chickens raised for eggs are usually called laying hens whilst chickens raised for meats are called broilers. 
There are droppings from poultry animals, most of which are often used as manure. Usually, these droppings contain harmful micro-organism, such as Salmonella spp., Enterococci spp., Escherichia coli, Campylobacter spp, Listeria monocytogenes and many others from the feed, contaminated water consumed and poultry produce. The harmful microorganisms often have multiple antibiotics resistance due to the misuse of antibiotic in poultry farming (Jones, 2007).

Antibiotics and other antibacterial drugs are the major weapons against disease-causing bacteria. They act in a number of ways to kill bacteria or suppress their activity. Over time, however, bacteria can become resistant to antibiotics (Funso and Folakemi, 2013). Extensive use and misuse of antibiotics in medication, veterinary, agriculture and aquaculture have increased the occurrence of antibiotic resistance bacteria in the natural environment (Kummerer, 2004). Resistance genetic material transfer from environmental bacteria to commensal microflora may also cause bacterial pathogens to carry antibiotic resistance, complicating disease prevention and treatment (Kummerer, 2004; Levy and Marshall, 2004).

In October 2000, the U.S Food and Drug Administration (FDA) discovered that two antibiotics were no longer effective in treating diseases found in factory-farmed chickens; antibiotic was swiftly pulled from market, but the other, Baytril was not until July 2005 (Pechere et al., 2005). Antibioticresistant organisms in domestic animals such as poultry, beef and swine are well documented (Prithwiray et al., 2008) and have been implicated as reservoirs for multidrug-resistant food borne pathogens. Also unsound practices in the pharmaceutical manufacturing industry such as production of counterfeit drugs can contribute towards the likelihood of creating antibiotic resistant strains (Larson and Fick, 2009). Emergence of bacteria resistant to antibiotics is common in areas where antibiotics are used, but occurrence of antibiotic resistance bacteria is also increasing in freshwater basins (Ash et al., 2002).

Therefore, the present study was carried out to isolate and identify antibiotic resistant bacteria from poultry well water and poultry droppings from government and private poultries, and also to determine their antibiotic susceptibility patterns.

\section{Materials and Methods}

\section{Sample Collection}

A total of 240 samples, containing Faecal droppings, well waters and antibiotic treated waters from the poultries were randomly and aseptically collected separately. The feacal droppings were collected with the aid of sterile swab stick and transferred immediately to sterile nutrient broth in sterile screw capped test tubes. Nevertheless, the water samples (Raw and Antibiotic treated), were collected aseptically into a sterile $500 \mathrm{ml}$ Schott Durham bottles, transported on ice to the Microbiology Laboratory in Ekiti State University, Ado Ekiti, Nigeria. All samples were analyzed within 1 hour of collection.

\section{Isolation and Characterization of Microbes}

In all cases, broth containing faecal droppings and water samples were shaken vigorously, and dilutions were prepared in sterile saline $(0.9 \mathrm{~g} \mathrm{NaCl} / 100 \mathrm{ml}$ of sterile distilled water). Triplicate plates were used for each sample dilution. The original numbers of organisms $(\mathrm{CFU} / \mathrm{ml})$ in water 
samples and faecal droppings were calculated considering the dilution factor and the final estimate was taken as the average of figures obtained from the countable plates (APHA, 1995). After preparation of ten fold serial dilution of the samples one millimeter $(1 \mathrm{ml})$ of each dilution factors- $10^{-3}, 10^{-4}$ and $10^{-6}$ were drawn aseptically from each dilution tubes and inoculated into sterile Petri dishes. The media were then added to the plates after cooling to about $45^{\circ} \mathrm{C}$. Each plates of the same sample were known to contained nutrient agar for one, MacConkey agar and Eosin methylene blue for the other. Plates were allowed to cool and set after which they are then incubated in inverted position at $37^{\circ} \mathrm{C}$. After $24 \mathrm{hrs}$ of incubation, the plates were counted with colony counter to obtain the total bacterial counts respectively (Barrow and Feltham, 1993). Pure cultures of isolated bacteria were characterized and identified using Bergey's manual of determinative bacteriology (Buchanaaan and Gibbon, 1974; Holt et al., 1997) and pure cultures of isolates were kept on nutrient agar slants at $12^{\circ} \mathrm{C}$ until used.

\section{Antibiotic Sensitivity Testing}

Antibiotic resistance of isolated bacteria was determined by disc diffusion method with the use of Mueller-Hinton agar, according to the CLSI guidelines for antimicrobial testing (CLSI, 2005). ABTEK Antibiotic discs with appropriate concentrations (given in parentheses) in accordance to the recommendation by the National Committee for Clinical Laboratory Standards (NCCLS, 2006), were used in this work. These include: Amoxicillin (AMX)-25 $\mu \mathrm{g}$, Ofloxacin (OFL)-5 $\mu$ g, Augmentin (AUG)-

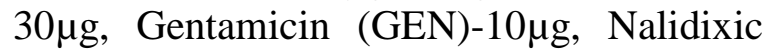
acid (NAL)-30 $\mu$ g, Nitrofurantoin (NIT)-

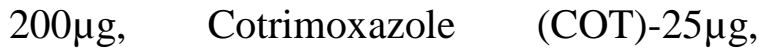
Tetracycline (TET)-25 $\mu \mathrm{g}$, Cloxacillin

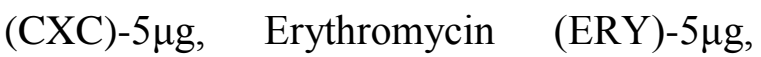
Chloramphenicol (CHL)-30 $\mu$ g, and Streptomycin (STR)-10 $\mu$ g. The inoculum was standardized by adjusting its density to equal the turbidity of a Barium sulphate $\left(\mathrm{BaSO}_{4}\right)(0.5 \mathrm{McFarland}$ turbidity standard), and incubated at $35^{\circ} \mathrm{C}$ for $18 \mathrm{~h}$. After incubation, a clear circular zone of inhibition in the immediate vicinity of a disk indicated susceptibility to that antibiotic. Using reference tables, the size of zones was related to the Minimum Inhibitory Concentration (MIC) and results recorded as whether the organism is susceptible $(\mathrm{S})$, Intermediate (I) or resistant (R) to that antibiotic (Funso and Folakemi, 2013).

\section{Results and Discussion}

The occurrence of the 200 isolates from raw water, antibiotic treated waters and faecal droppings gotten from the examined poultries (Table 1), revealed that $48(24 \%)$ were Escherichia coli, 20(10\%) were Pseudomonas, 21(10.5\%) were Klebsiella, $3(1.5 \%)$ were Proteus, $1(0.5 \%)$ was Enterobacter, each of Serratia and Acetobacter 4(2\%) respectively, 61(30.5\%) were Staphylococcus, 6(3\%) were Streptococcus, 23(11.5\%) were Micrococcus and $9(4.5 \%)$ were Bacillus. The isolates were mostly enteric organisms.

Table 2 shows Escherichia coli had 63\% resistance to augmentin, $56 \%$ resistance to ofloxacin, $73 \%$ resistance to gentamicin, $69 \%$ to nalixidic acid, $75 \%$ to nitrofurantoin and amoxicillin respectively, $71 \%$ to cotimoxazole and $69 \%$ to tetracycline. Pseudomonas spp. recorded $70 \%$ resistance to augmentin, $45 \%$ resistance to ofloxacin, $65 \%$ resistance to gentamicin, nitrofurantoin, cotrimoxazole and amoxicillin respectively, $80 \%$ resistance to nalixidic acid and $55 \%$ resistance to tetracycline. Klebsiella had $76 \%$ resistance 
to augmentin, $52 \%$ resistance to ofloxacin, $62 \%$ resistance to gentamicin, amoxicillin and tetracycline respective, $67 \%$ resistance nalixidic acid and nitrofurantoin; with $71 \%$ resistance to cotrimoxazole. Also, Proteus showed $67 \%$ resistance to augmentin and gentamicin respectively, $33 \%$ resistance to ofloxacin, nalixidic acid and cotrimoxazole respectively, $100 \%$ resistance to nitrofurantoin and amoxicillin respectively; with $100 \%$ susceptibility to tetracycline. Enterobacter had $100 \%$ susceptibility to ofloxacin, gentamicin and tetracycline respectively; with $100 \%$ resistance to augmentin, nalixidic acid, nitrofurantoin, cotrimoxazole and amoxicillin respectively. Serratia had $75 \%$ resistance to augmentin, gentamicin, nitrofurantoin, cotrimoxazole and amoxicillin respectively, $25 \%$ resistance to Ofloxacin and $50 \%$ resistance to nalixidic acid and tetracycline respectively. Nevertheless, Acetobacter showed $75 \%$ resistance to augmentin, nalixidic acid and amoxicillin respectively, $25 \%$ resistance to ofloxacin, $50 \%$ resistance to gentamicin, cotrimoxazole and tetracycline respectively, and $100 \%$ resistance to nitrofurantoin.

Table 3 on the other hand has Staphylococcus being $66 \%$ resistant to cotrimoxazole, augmentin and streptomycin respectively, $67 \%$ resistance to cloxacillin and erythromycin respectively, $62 \%$ resistance to gentamycin and tetracycline respectively; with $29 \%$ resistance to chloramphenicol.

Streptococcus had $83 \%$ resistance to cotrimoxazole and cloxacillin respectively, $50 \%$ resistance to erythromycin streptomycin and tetracycline respectively, $16 \%$ resistance to gentamycin and chloramphenicol respectively, and $67 \%$ resistance to augmentin. Also, Micrococcus showed $70 \%$ resistance to cotrimoxazole and streptomycin respectively, $65 \%$ resistance to cloxacillin and erythromycin respectively, $35 \%$ resistance to tetracycline and chloramphenicol respectively, and $48 \%$ resistance to gentamycin. Nevertheless, Bacillus showed $67 \%$ resistance to cotrimoxazole, cloxacillin, and erythromycin, $44 \%$ resistance to gentamycin and streptomycin respectively, $56 \%$ resistance to tetracycline and chloramphenicol respectively and $78 \%$ resistance to Streptomycin.

Results from this study shows that the faecal sample in both poultries showed a high level of microbial load and coliform count compared to the water samples, which is related to the research carried out by (Adeguloye, 2006), where he recorded a high microbial load in faeces compared to poultry water and foods. It is as a result of faeces having organic compound/nutrient that tends to facilitate the growth, and also the intestinal tract of animals is mostly inhabited by microorganisms (Mead, 2000), many of which are enteric bacteria; hence serving as major source of the isolated enteric bacteria. Staphylococcus showed the highest number of occurrence of $61(30.5 \%)$, followed by Escherichia coli 48(24\%), Micrococcus 23 (11.5\%), Klebsiella 21 (10.5\%), Pseudomonas 20 (10\%), Bacillus 9 (4.5\%), Streptoccocus 6 (3\%), Serratia and Acetobacter 4 (2\%) respectively, Proteus 3 (1.5\%), and Enterobacter 1(0.5\%). This high level of Staphylococcus and E. coli occurrence was similar to the report of (Apajalaty et al., 2002), who reported a high occurrence of Staphylococcus and E. coli in the intestinal tracts of poultry animals.

Generally from this study, gram negative organisms showed a high resistance to all the antibiotics used; with ofloxacin showing the most action towards virtually the organisms i.e most of the organisms are sensitive to ofloxacin. 
Table.1 Bacteriological count (CFU/ml) of raw water, faecal and antibiotic water samples

\begin{tabular}{|c|c|c|c|c|c|c|c|c|c|c|c|c|}
\hline \multirow[t]{3}{*}{ Samples } & \multicolumn{4}{|c|}{ A } & \multicolumn{4}{|c|}{ B } & \multicolumn{4}{|c|}{$\mathrm{C}$} \\
\hline & \multicolumn{2}{|c|}{ TBC } & \multicolumn{2}{|c|}{ TCC } & \multicolumn{2}{|c|}{ TBC } & \multicolumn{2}{|c|}{ TCC } & \multicolumn{2}{|c|}{ TBC } & \multicolumn{2}{|c|}{ TCC } \\
\hline & $10^{4}$ & $10^{5}$ & $10^{4}$ & $10^{5}$ & $10^{4}$ & $10^{5}$ & $10^{4}$ & $10^{5}$ & $10^{4}$ & $10^{5}$ & $10^{4}$ & $10^{5}$ \\
\hline PP1 & 1.1 & 1.0 & 1.0 & 0.5 & 13.6 & 10 & 10 & 3.3 & 1.0 & 0.6 & 1.2 & 0.7 \\
\hline PP2 & 0.7 & 0.4 & 0.4 & 0.1 & 14.2 & 6.5 & 9.8 & 4.3 & 1.2 & 0.2 & 0.4 & 0.3 \\
\hline PP3 & 0.4 & 0.3 & 0.7 & 0.2 & 13.7 & 8.2 & 7.8 & 3.9 & 1.2 & 0.1 & 0.9 & 0.7 \\
\hline PP4 & 0.3 & 0.2 & 0.4 & 0.2 & 12.6 & 8.0 & 6.9 & 3.5 & 1.3 & 0.4 & 0.2 & 0.1 \\
\hline PP5 & 0.5 & 0.2 & 0.4 & 0.1 & 12.3 & 6.5 & 4.4 & 3.0 & 1.2 & 0.5 & 1.0 & 0.4 \\
\hline Mean & 0.6 & 0.4 & 0.6 & 0.2 & 13.3 & 7.8 & 7.8 & 3.6 & 1.2 & 0.4 & 0.7 & 0.4 \\
\hline EKSU1 & 0.4 & 0.2 & 0.4 & 0.3 & 10.1 & 7.9 & 3.5 & 2.0 & 0.5 & 0.3 & 2.0 & 0.1 \\
\hline EKSU2 & 0.6 & 0.3 & 0.5 & 0.3 & 8.7 & 5.2 & 4.1 & 2.0 & 1.3 & 0.7 & 0.5 & 0.3 \\
\hline EKSU3 & 1.0 & 0.7 & 1.2 & 0.4 & 9.0 & 6.2 & 5.0 & 4.6 & 2.0 & 1.6 & 1.1 & 0.4 \\
\hline EKSU4 & 1.0 & 0.2 & 0.4 & 0.3 & 8.2 & 7.0 & 6.3 & 5.5 & 1.8 & 1.2 & 0.8 & 0.6 \\
\hline EKSU5 & 0.7 & 0.3 & 1.0 & 0.4 & 7.0 & 5.2 & 5.0 & 4.1 & 1.2 & 1.0 & 0.8 & 0.3 \\
\hline Mean & 0.7 & 0.3 & 0.7 & 0.3 & 8.6 & 6.3 & 4.7 & 3.6 & 1.3 & 0.9 & 1.0 & 0.3 \\
\hline
\end{tabular}

Key: TBC - Total Bacteria Count $\quad$ TCC - Total Coliform Count

A - Raw water B - Faecal C - Antibiotics contained water

PP - Private poultry

EKSU - Ekiti State University poultry 
Table.2 Percentage distribution of bacterial isolates from private poultries

\begin{tabular}{|c|c|c|c|c|c|}
\hline Isolates & $\mathbf{A}$ & B & $\mathrm{C}$ & $\begin{array}{l}\text { Total } \\
\text { number of } \\
\text { occurrence }\end{array}$ & $\begin{array}{l}\text { Percentage of } \\
\text { occurrence } \\
(\%)\end{array}$ \\
\hline $\begin{array}{l}\text { Staphylococcus } \\
\text { spp }\end{array}$ & 8 & 6 & 7 & 21 & 23.3 \\
\hline Proteus spp & 2 & 1 & - & 3 & 3.33 \\
\hline Pseudomonas spp & 5 & 4 & 2 & 11 & 12.2 \\
\hline E. coli & - & 9 & 16 & 25 & 27.8 \\
\hline Acetobacter spp & 1 & - & - & 1 & 1.1 \\
\hline Streptococcus spp & - & 1 & - & 1 & 1.1 \\
\hline Bacillus spp & - & 1 & 2 & 3 & 3.33 \\
\hline Micrococcus spp & 7 & 1 & 5 & 13 & 14.4 \\
\hline Serratia spp & - & 1 & - & 1 & 1.1 \\
\hline Klebsiella spp. & 2 & 6 & 2 & 10 & 11.1 \\
\hline Enterobacter spp. & - & - & 1 & 1 & 1.1 \\
\hline Total & 25 & 30 & 35 & 90 & 100 \\
\hline
\end{tabular}

Key: $A=$ Raw water sample

$\mathrm{B}=$ Feacal sample

$\mathrm{C}=$ Antibiotic water sample 
Table.3 Percentage distribution of bacteria isolated from examined poultries

\begin{tabular}{lcc}
\hline Organisms & $\begin{array}{c}\text { No of Isolates } \\
\mathbf{n = 2 0 0}\end{array}$ & $\begin{array}{c}\text { Percentage } \\
(\mathbf{\%})\end{array}$ \\
\hline Staphylococcus spp. & 61 & 30.5 \\
Escherichia coli & 48 & 24 \\
Micrococcus spp. & 23 & 11.5 \\
Klebsiella spp. & 21 & 10.5 \\
Pseudomonas spp. & 20 & 10 \\
Streptococcus spp. & 6 & 3 \\
Serratia spp. & 4 & 2 \\
Acetobacter spp. & 4 & 2 \\
Proteus spp. & 3 & 1.5 \\
Enterobacter spp. & 1 & 0.5 \\
\hline
\end{tabular}

Key: $\mathrm{n}=$ Total number of isolated bacteria.

Table.4 Percentage antibiotic resistance of gram negative bacteria from examined poultries

\begin{tabular}{ccccccccc}
\hline Organisms & $\begin{array}{c}\text { AUG } \\
(\boldsymbol{\%})\end{array}$ & $\begin{array}{c}\text { OFL } \\
(\boldsymbol{\%})\end{array}$ & $\begin{array}{c}\text { GEN } \\
(\boldsymbol{\%})\end{array}$ & $\begin{array}{c}\text { NAL } \\
(\boldsymbol{\%})\end{array}$ & $\begin{array}{c}\text { NIT } \\
(\boldsymbol{\%})\end{array}$ & $\begin{array}{c}\text { COT } \\
(\boldsymbol{\%})\end{array}$ & $\begin{array}{c}\text { AMX } \\
(\boldsymbol{\%})\end{array}$ & $\begin{array}{c}\text { TET } \\
(\boldsymbol{\%})\end{array}$ \\
\hline Escherichia. coli & 63 & 54 & 73 & 69 & 75 & 71 & 75 & 69 \\
Pseudomonas spp. & 70 & 45 & 65 & 80 & 65 & 65 & 65 & 55 \\
Klebsiella spp. & 76 & 52 & 62 & 67 & 67 & 71 & 62 & 62 \\
Proteus spp. & 67 & 33 & 67 & 33 & 100 & 33 & 100 & 0 \\
Enterobacter spp. & 100 & 0 & 0 & 100 & 100 & 100 & 100 & 0 \\
Serratia spp. & 75 & 25 & 75 & 50 & 75 & 75 & 75 & 50 \\
Acetobacter spp. & 75 & 25 & 50 & 75 & 100 & 50 & 75 & 50 \\
\hline
\end{tabular}

Key: AUG- Augmentin, OFL- Ofloxacin, GEN- Gentamycin, NAL- NAlixidic acid, NITNitrofurantoin, COT- Cotrimoxazole, AMX- Amoxicillin, TET- Tetracycline. 
Table.5 Percentage Antibiotic Resistance of Gram Positive bacteria from examined poultries

\begin{tabular}{ccccccccc}
\hline Organisms & $\begin{array}{c}\text { COT } \\
(\boldsymbol{\%})\end{array}$ & $\begin{array}{c}\text { CXC } \\
(\boldsymbol{\%})\end{array}$ & $\begin{array}{c}\text { ERY } \\
(\boldsymbol{\%})\end{array}$ & $\begin{array}{c}\text { GEN } \\
(\boldsymbol{\%})\end{array}$ & $\begin{array}{c}\text { AUG } \\
(\boldsymbol{\%})\end{array}$ & $\begin{array}{c}\text { STR } \\
(\boldsymbol{\%})\end{array}$ & $\begin{array}{c}\text { TET } \\
(\boldsymbol{\%})\end{array}$ & $\begin{array}{c}\text { CHL } \\
(\boldsymbol{\%})\end{array}$ \\
\hline Staphylococcus spp. & 66 & 67 & 67 & 62 & 66 & 66 & 62 & 29 \\
Streptococcus spp. & 83 & 83 & 50 & 16 & 67 & 50 & 50 & 16 \\
Micrococcus spp. & 70 & 65 & 65 & 48 & 74 & 70 & 35 & 35 \\
Bacillus spp. & 67 & 67 & 67 & 44 & 44 & 78 & 56 & 56
\end{tabular}

Key: COT- Cotrimoxazole, CXC- Cloxacillin, ERY- Erythromycin, GEN- Gentamycin, AUGAugmentin, STR- Streptomycin, TET- Tetracycline, CHL- Chloramphenicol.

Similar observation was shown by (Funso and Folakemi, 2013), who showed high resistance of Gram negative organisms isolated from poultry samples against all the antibiotics used. On the other hand, Gram positive organisms isolated showed susceptibility mostly to chloramphenicol and high resistance to other antibiotic used. This is also similar to what was observed by (Macovel, 2006). Macovel observed low resistance percentage to chloramphenicol, but high resistance percentage to other antibiotics when tested against gram positive organisms. The multiple antibiotic resistances of these bacterial isolates are suggestive that the bacterial isolates arose from the source of high level of antibiotic selective pressure, resulting from the misuse of antibiotics in poultry farming (Apata, 2009).

\section{Conclusion and Recommendation}

The result obtained in this study showed that poultry samples (raw water, faeces and antibiotic treated waters) contained bacteria with multiple antibiotic resistance patterns, which may be caused by horizontal transfer of resistance genes among non related bacteria isolates. It also shows that farm environmental samples are reservoir of antibiotic resistance species, thus recommending proper hygiene as well as proper use of antibiotics in poultry. This study therefore recommends the regulation of the use of antibiotics for prophylaxis, therapeutics and growth population by appropriate government veterinary agencies. Also, a creation of resistance surveillance system through permanent monitoring programs to assess resistance in pathogenic indicator and zoonotic bacteria species should be encouraged in order to safe-guide animal and human health. Ofloxacin is however recommended for the treatment of bacterial infections in poultry farming.

\section{References}

Adegunloye, D.V. 2006. Microorganisms associated with poultry faeces. J. food Agri. Environ., 4: 41-42.

American Public Health Association (APHA). 1995. Standard methods for the examination of water and wastewater. 19th ed. American Public Health Association; Washington, D.C. Apajalahty, J.H., Kettunen, H., Kettunen A., Holben, W.E., Nurminen, P.H., Rautonen, N. and Mutanen, M. 2002. Culture-independence microbial community analysis reveals that Inulin in the diet primarily affects previously unknown Bacteria in the Mouse cecum. Appl. Environ. Microbiol., 68: 4986-4995. 
Apata, D.F. 2009. Antibiotic resistance in poultry. Int. J. Poult. Sci., 8: 404 408.

Ash, R.J., Mauck, B. and Morgan, M. 2002. Antibiotic resistance of gram-negative bacteria in rivers, United States. Emergence Infect. Dis., 8: 713-716.

Barrow, G.I., and Feltham, R.K.A. 1993. Cowan and Steel's Manual for the Identification of Medical Bacteria, 3rd edn. Cambridge: Cambridge University Press.

Bauer, A.W., Kirby, W.M. and Sherris, J.C. 1966. Antibiotics susceptibility testing by a standardized single disk method. American J. Clin. Pathogenicity, 45: 493-496.

Buchanaan, R.E. and Gibbons, N.E. 1974. Bergey's manual of determinative bacteriology. $8^{\text {th }}$ Edition, The Williams and Wilkins Company, Baltimore.

Funso, O. and Folakemi, O. 2013. Antibiotic resistance pattern of bacterial pathogens isolated from poultry manure used to fertilize fish ponds in New Bussa, Nigeria. Albaniam $J$. Agri., 12(1): 81-85.

Holt, G.H., Kreig, N.R., Sneath, P.H.A., Staley, J.T. and Williams, S. 1997. Bargey`s Manual of Determinative Bacteriology: Williams and Wilkins, New York: 1997.

Kummerer, K. 2004. Resistance in the environment. J, Antimicrobial Chemother., 54: 311-320.

Larson, D.G. and Fick, J. 2009. Transperency throughout the production chain- a way to reduce pollution from the manufacturing of pharmaceuticals. Regulated Toxicol. Pharmacol., 53:161-?.

Levy, S.B. and Marshall, B. 2004. Antibacterial resistance worldwide: causes, challenges and responses. National Med., 10: 122-129.

Macovei, L. and Zurek, L. 2006. Ecology of antibiotic resistance genes: characterization of Enterococci from houseflies collected in food settings. App. Environ. Microbiol., 72: 40284035.

Mead, G.C. 2000. Prospects for competitive exclusion treatment to control Salmonella and other food borne pathogens in poultry. Vet. J., 159: 11123.

National committee for clinical laboratory standards $\quad 2006$. Performance standards for Antimicrobial susceptibility testy: 4th edition.

Pechere, J.C., Hughes, D., Kardas, P. and Cornaglia, G. 2007. 'Non-compliance with antibiotic therapy for acute community infections: a global survey“. Int. J. Antimicrobial Agents, 29(3): 245-53.

Prithwiray, J., Sudip, B. and Chitta, R.N. 2008. Fish production, water quality and bacteriological parameters of Koi carp ponds under live-food and manure based management regimes. Zool. Res., 29(2): 165-173.

\section{How to cite this article:}

Odeyemi, A.T., and Omotoso, O.E. 2016. Antibiotic Resistance Patterns of Isolated Bacteria from Government and Private Poultries Water Samples in Ado-Ekiti. Int.J.Curr.Microbiol.App.Sci. 5(9): 111-119. doi: http://dx.doi.org/10.20546/ijcmas.2016.509.013 